\section{Fotojornalismo cidadão: comentário sobre contradições na fé redentora da cidadania}

Douglas Feitosa Romão
Recebido em: 25.06.20

Aprovado em: 05.02.21

Douglas Feitosa Romão

Doutorando em Comunicação pelo PPGCOM - UFF

E-mail: romao.doug@ gmail.com

\title{
Resumo:
}

Vamos discutir neste artigo algumas das potências e contradições depositadas na esperança de democratização da cidadania após a ampliação do consumo de massa de dispositivos móveis inteligentes, sobretudo no uso de um conceito alargado de fotojornalismo, qual seja, o fotojornalismo cidadão. Esperamos apresentar alguns contrapontos que criticam uma possível diluição do jornalismo ou fotojornalismo clássico no jornalismo cidadão ou fotojornalismo cidadão. Além disso, pretendemos aproximar as contradições às quais estão sujeitos os agentes do chamado "midialivrismo" e do fotojornalismo profissional.

Palavras-chave: Midialivrismo. Testemunho. Fotojornalismo.

Citizen photojournalism: a comment on the contradictions in the faith of citizenship redemption

\begin{abstract}
:
We will discuss in this article some of the powers and contradictions deposited in the hope of democratizing citizenship after the expansion of mass consumption of smart mobile devices, especially in the use of a broad concept of photojournalism, namely, citizen photojournalism. We hope to present some counterpoints that criticize a possible dilution of journalism or classic photojournalism in citizen journalism or citizen photojournalism. In addition, we intend to approach the contradictions that are subject to the agents of the so-called "midialivrismo" and professional photojournalism.
\end{abstract}

Keywords: Midialivrismo. Testimony. Photojournalism. 


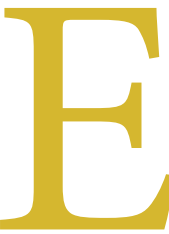

m meados dos anos 2000, muito se discutiu sobre a apropriação da tecnologia telemática como maneira de aumentar o engajamento do cidadão comum através da expansão da internet, a criação de redes sociais mais interativas, e, não menos importante, a sobrevivência dos veículos clássicos de comunicação: imprensa, televisão e rádio. Por um momento, a internet e a cultura de meios colaborativos que se avizinhavam seriam o lugar da redenção da democracia, onde os indivíduos poderiam colaborativamente fazer um contraponto aquilo que se imaginava falho nas grandes corporações, fosse por motivações comerciais ou políticas. Cada indivíduo poderia tornar-se um jornalista em potencial, cada jornalista um cidadão atento aos problemas da região onde vivia. Sob uma forma de "economia da dádiva" em que todos ofertariam algo a ser consumido por todos, produtores-consumidores estariam interessados na manutenção de trocas simbólicas. A audiência passaria a ser produtora ou auxiliar na produção corrente da informação de valor noticioso; lembrando que algumas dessas características há muito tempo estavam presentes na relação da audiência com os veículos de comunicação.

Apesar do tom positivo e da fé depositada na articulação produtiva da audiência, algumas consequências passaram a ser cogitadas. Uma delas seria a diluição do jornalismo profissional em jornalismo cidadão (MORETZHON, 2014). Afinal, se todos poderiam ser jornalistas em potencial, a profissionalização perderia o seu efeito. Outra questão seria que, partindo do progresso tecnológico de dispositivos móveis em sistemas cada vez mais inteligentes e com recursos fotográficos cada vez mais robustos, um outro terreno do jornalismo também poderia ser questionado: a fotografia de imprensa (BONI; SOUZA, 2008). Além disso, um fato que vem sendo tratado amiúde é a circulação de informações sem credibilidade, sobretudo pela falta de mecanismos de checagem e filtros, as assim chamadas fake news (MORETZHON, 2014; 2019).

\section{O voluntarismo e a dádiva}

Ao observarmos a relação entre dispositivos móveis e consumidores, poderíamos tender a recortá-la em uma realidade cuja produção econômica é mais significativa e reguladora nas relações de consumo. No entanto, procuramos aqui compreender a realidade posta por meio do uso que se faz desses objetos, sem recorrer a um viés moralizante, compreendendo o consumo como um mediador de relações sociais. Um termo síntese para cultura material na definição do antropólogo Daniel Miller são os "trecos" (stuff), objetos elaborados criando não algo intrinsecamente bom ou mau, mas elementos aparentemente contraditórios na relação humana com as coisas, isto é, como "as coisas fazem as pessoas" (MILLER, 2010, p. 66). Parece-nos particularmente interessante como esses objetos adquirem significações diversas conforme suas diferentes apropriações, fazendo inclusive dos afetos matéria dessas próprias relações extrapolando uma função meramente utilitarista. Por exemplo, pessoas que utilizam smartphones para registrar o cotidiano de um bairro que precisa de maior atenção do poder público.

Bens são necessários e produzidos por todas as sociedades, na medida em que atendem questões de subsistência, desde a comida até funções utilitárias. Mas como estabelecem Douglas \& Isherwood (2013), os bens podem ser acessórios rituais e o consumo um processo ritual do dar sentido à característica de incompletude do fluxo de acontecimentos. Enquanto consumidores, os indivíduos parecem ter como necessário dar inteligibilidade a seu universo por meio de seus bens. Estes bens, podemos pensar, seriam a parte visível da cultura cujas estruturas seriam ancoradas nos projetos sociais humanos, como dizem Douglas \& Isherwood (2004, p. 105) "ao mesmo tempo, é evidente que os bens têm outro uso importante: também estabelecem e mantêm relações sociais”. 
Partindo dessas constatações, objetivamos indagar se com a ampliação do consumo de dispositivos móveis, mais que gerar um círculo de consumo com fim em si mesmo, que retroalimenta a cadeia produtiva, esse fenômeno não contribuiria para formas de sociabilidades com um alcance sem o qual seria muito mais restritivo ou inexistente. A partir de uma pesquisa nacional da consultoria Deloitte, a Global Mobile Consumer Survey 2017, apenas no Brasil em 2017, constatou-se que $87 \%$ dos entrevistados utilizavam smartphones, $62 \%$ pretendiam obter um novo dispositivo e $31 \%$ costumavam doar seus dispositivos usados a familiares ou amigos. Este último dado parece interessante, pois os usuários influenciam diretamente na ampliação de suas redes de sociabilização. A pesquisa ainda apresentou que $42 \%$ dos usuários utilizavam seus dispositivos para leitura de notícias diariamente, sendo seu terceiro maior uso. Além disso, 55\% compartilhavam fotografias por mensagens instantâneas e 34\% faziam postagem de imagens em redes sociais, a mbos diariamente. Além disso, segundo a 29a Pesquisa Anual do Uso de TI da FGV EAESP há no Brasil mais de 220 milhões desses dispositivos em uso.

Consideraremos para este raciocínio as atitudes voluntárias de fazer circular informações contribuindo para o fluxo de uma informações em tempo-real. Para isso, utilizaremos a noção de jornalismo cidadão. Nela, entendemos que uma pessoa munida com ferramentas tecnológicas necessárias pode produzir informações, horizontalizando, portanto, a prática e a distribuição da mesma. Trata-se, assim, de uma perspectiva mais libertária, em oposição à centralização costumeira das organizações midiáticas comerciais ou governamentais (MORETZSOHN, 2014).

Esta noção é muito semelhante ao que já vinha ocorrendo em escala menor com agremiações políticas libertárias como o CMI (Centro de Mídia Independente - Indymedia) que tinha o objetivo de formar voluntários produtores de informações independentes de organizações comerciais e governamentais na virada dos anos 2000, sobretudo de caráter anticapitalista e que cresceu vertiginosamente após os chamados Protestos de Seattle (SKOGESETH, 2005). Devido ao seu caráter político e contrário à centralização de informações, adequaram-se às concepções em voga nas comunidades hackers e linuxers da época, isto é, utilizando plataformas de software livre e liberando suas produções em copyleft. Até hoje atuam na capacitação, sobretudo de movimentos sociais, com oficinas de redação, repórteres cidadãos, fotografia, informática, dentre outros. Parece, portanto, a constituição desse tipo de coletivo muito similar aquilo que, nas reflexões de Renata Apgaua (2004) sobre o surgimento e consolidação do sistema operacional Linux, são característicos de um espaço de sociabilidade com uma lógica diferente do mercado e que apontaria sobre a atualidade do conceito de dádiva tratado por Marcel Mauss em seu "Ensaio sobre a dádiva: forma e razão da troca nas sociedades arcaicas.” (1974), na medida em que relações arcaicas ainda persistiriam em sociedades modernas. Segundo a autora, em um primeiro momento do surgimento do sistema operacional, a comunidade se organizava em certo aspecto sob a perspectiva da dádiva, mas ao se relacionar com os meios corporativos teria abrigado um "paradoxo de gratuidade" do ponto de vista do mercado. Afinal, para o pensamento mercantil a dádiva seria o gratuito e uma retribuição seria considerada troca, portanto baseado no interesse mercadológico. Por isso, segundo Apgaua (2004, p. 230):

Não se pode esquecer do sentimento de dívida que acompanha aqueles que retribuem, por pensarem que receberam mais do que efetivamente retribuíram - o retorno na dádiva não obedece às regras da equivalência mercantil. A dádiva escapa ao modelo mercantil, por suas características paradoxais, como: gratuidade e retorno, interesse e desinteresse, liberdade e obrigação, desigualdade nas trocas, prazer em dar, espontaneidade, fortalecimento do vínculo, etc. 
Essa relação de desigualdade que inicialmente parece estranha, como se fosse um mal negócio do ponto de vista do mercado, foi percebida por Graham Murdock (2010) ao comentar sobre trabalhos colaborativos de jornalismo cidadão em um estudo sobre 3 mil fotografias a respeito de um desfile em Nova York no Flickr - rede social de fotografias. Neste caso foi percebido que dez usuários eram responsáveis por metade das postagens, enquanto outros ficavam numa relação de 1/12. Assim, a dádiva não parecia ser algo desinteressado, mas simplesmente privilegiava alguns interesses, como alianças e solidariedade, criando um tipo de laço espiritual em que a coisa carregava algo de seu doador. Como diz Mauss (1974, p. 190):

Trata-se, no fundo, de misturas. Misturam-se as almas nas coisas, misturam-se as coisas nas almas. Misturam-se as vidas, e assim as pessoas e as coisas misturadas saem cada qual de sua esfera e se misturam: o que é precisamente o contrato e a troca.

Em algumas situações poderíamos dizer, então, que essa distinção entre usuários criava prestígio, como se o compartilhado carregasse a alma do possuidor promovendo vínculos de obrigações mútuas e crescentes. Algo visível, segundo Murdock (2010), nos meios digitais onde a relação de trabalho é em boa medida freelance, de modo que a visibilidade e conexões sociais ajudam a garantir alguma "empregabilidade". Isso, segundo o autor, é ainda mais intenso em meio à juventude que se utiliza naturalmente dos meios digitais criando uma economia emergente de conhecimento cujo locus de inovação da cadeia controlada pela indústria move-se e se expande em um sistema aberto complexo onde todos são agentes ativos (MURDOCK, 2010) e efetuam essas trocas.

Em um primeiro momento, poderíamos acreditar que as relações estabelecidas nas comunidades produtoras, por exemplo, de fotografias do cotidiano, garantiriam que os agentes participativos não teriam interesse de criar condições para o descrédito de suas comunidades, ainda que dissessem claramente que toda a produção de informações é parcial. Geralmente, por força de oposição ao controle comercial e governamental ataca-se justamente a suposta imparcialidade dos grandes veículos de informação, generalizando que todos são parciais (MALINI; ANTOUN, 2013). No entanto, uma questão nos salta quando nos referimos à comunicação e informações providas por jornalistas cidadãos: não haveria um risco sobre o compromisso ético no tratamento informacional, pois a comunidade parece ficar sujeita a ecos, erros, perversidades dos agentes envolvidos, seus afetos, ou simplesmente maior visibilidade de suas marcas? Acerca da tensão entre essas duas posições comentaremos adiante.

\section{A serviço da cidadania}

Sob uma perspectiva positiva, Paulo Cesar Boni e Fabio Dias de Souza (2008) colocam o jornalismo cidadão como uma decorrência de espaços ao leitorado desde os anos 1970 por jornais reconhecidos e potencializado pela internet. Desse modo, dois caminhos se apresentam: por um lado, citando dois exemplos, a criação de sites colaborativos como o OhMyNews, cujo lema "todo cidadão é um repórter" relaciona o trabalho de uma maioria amadora produzindo informações revisadas e checadas por uma equipe profissional pequena e, como fotojornalismo cidadão, a Scoopt, uma agência que foi comprada pela Getty Images como um projeto de ampliação de seu conceito de fotojornalismo e que posteriormente foi abandonado; por outro lado, o exemplo de veículos tradicionais que tentam se adequar a um ambiente digital mais interativo ou participativo, como os brasileiros $O$ Estado de S. Paulo e Jornal de Londrina.

O registro que fazem os autores é na expectativa do exercício da cidadania conforme os agentes envolvidos passam a utilizar esses meios de modo a obterem 
benefícios do poder público sobre localidades possivelmente com problemas. No entanto, para que isso surtisse algum efeito, percebeu-se que a filtragem e curadoria dos veículos midiáticos envolvidos precisou descartar, em seu início, imagens que não tinham interesse jornalístico, já que muitas delas eram "fotografias de flores ou festas" (BONI; SOUZA, 2008). Esta informação, apesar de parecer menor, faz-nos supor revelar um dos muitos aspectos possíveis que os agentes "fotorrepórteres" consideravam como válidos, de colocar suas almas, na relação que estabeleciam com o jornal de que eram consumidores, fazendo deles naquele momento um tipo de rede social. Não se tratando de responder, mas de levantar um questionamento acerca dessa relação, mutatis mutandis, diz Daniel Miller:

As mídias sociais deram à fotografia uma onipresença sem precedentes como parte da vida cotidiana. Onde tirar uma fotografia já foi uma espécie de mini evento, agora dezenas de imagens podem fluir em poucos minutos como uma conversa em andamento. Além disso, com a disseminação de smartphones, uma vasta população de famílias de baixa renda em todo o mundo tornou-se fotógrafos diários. (MILLER, 2016, p. 160, tradução nossa)

Se não fosse o controle sobre o valor de notícia imposto pelo jornal, seria possível que as imagens empregadas se assemelhassem a um modo de operação de publicações em redes sociais? Talvez sim, pois pareciam entender cidadania também como o ser reconhecido individualmente em contraste com a comunidade, a sociedade, a multidão, o anonimato. Como se quisessem revelar um momento da mais singular verdade, dentro de seu regime de credibilidade, como a experiência da própria vida.

Com o tempo, os cidadãos fotojornalistas passaram a se identificar com um aspecto mais comunitário, dizem os autores. Como citam em uma entrevista:

Oliveira diz que 30 fotografias suas já foram publicadas e que chegou até a receber uma ligação do órgão responsável pelo problema 'denunciado', prometendo providências. Exercendo seus direitos e deveres, diz que sua intenção é unicamente servir à comunidade, já que a maioria das pessoas dificilmente se expõe. 'Penso que, se cada um apontar, sugerir transformações e brigar para que o poder público mude sua postura, a cidade melhorará muito...' Ele pretende fotografar pontos críticos do trânsito e 'sugerir alterações simples e objetivas através do envio do material à imprensa’. (BONI; SOUZA, 2008, p. 29).

Para os autores, a fotografia funcionaria, então, como prática conscientizadora de modo que "a abertura oferecida por alguns veículos contribui para que as pessoas se transformem em sujeitos participativos da ação” Boni \& Souza (2008, p. 31), como protagonistas e não apenas receptores passivos.

Uma curiosidade é que poucos desses espaços tradicionais estabelecem relações mercantis com seus fotojornalistas cidadãos. Isso acaba gerando a possibilidade do fotojornalista cidadão comprar sua própria produção, no caso de um impresso, ou trocar dados pessoais de navegação online quando se trata de websites, afinal esses produtos e suas almas estariam misturados. Seria este caso novamente o da dádiva cuja coisa compartilhada é a própria cidadania? Ou como afirma Igor Kopytoff (2008, p. 1):

Do total de coisas disponíveis numa sociedade, apenas algumas são apropriadamente sinalizáveis como mercadorias. Além do mais, a mesma coisa pode ser tratada como uma mercadoria numa determinada ocasião, e não ser em outra. Finalmente, a mesma coisa pode, ao mesmo tempo, ser vista por uma pessoa como uma mercadoria, e como uma outra coisa por outra pessoa. Essas mudanças e diferenças nas circunstâncias e nas possibilidades de uma coisa ser uma mercadoria revelam uma economia moral subjacente à economia objetiva das transações visíveis.

Certamente existem problemas de diversas ordens que, nas relações entre o jornalismo cidadão e os veículos comerciais, não poderemos responder aqui. Mas 
gostaríamos de ressaltar o quanto é comum a crença na produção de cidadania a partir do desenvolvimento de novas tecnologias, como se elas pudessem de algum modo ser redentoras, quando, na verdade, há uma série de escolhas por parte dos indivíduos que ativam afetos que podem retroalimentar informações falsas simplesmente porque não passam pelo crivo da racionalidade iluminista em que se espera posição crítica dos sujeitos envolvidos. Além disso, costuma-se falar em cidadania como se houvesse um consenso a partir do qual se devesse guiar a vida democrática, porém, como reflete Sylvia Moretzsohn sobre o efeito das bolhas em redes sociais e as fake news:

veremos que ali se dá crédito às fake news, entretanto apresentadas como fatos - como verdades - a confirmarem as convicções de quem recebe e ajuda a espalhar essas informações. Dessa forma, o que importa, para esse público, não é discernir o verdadeiro do falso, como estamos acostumados a pensar, mas reiterar essas convicções. Então, a credibilidade continuaria a ser uma crença, mas não precisaria mais ser verdadeira, e se justificaria tautologicamente como forma de confirmá-la (MORETZSOHN, 2019, p. 578).

Para a autora, mesmo os mecanismos de checagem no jornalismo profissional cumprem um papel ideológico de legitimação das empresas jornalísticas "e participam do mesmo esforço de legitimação de um lugar histórico abalado pela explosão provocada com o surgimento da internet" (MORETZSOHN, 2019, p. 585). Desse modo, para a autora, é importante compreender a complexidade do ambiente da "infotelecomunicação" e questionar como ocorrem as trocas, os compartilhamentos, os retornos de notícias velhas como se fossem atuais, e as emulações dos regimes de credibilidade do jornalismo.

Moretzsohn (2014) já havia criticado como equivocada a ideia segundo a qual tecnologias alteram relações sociais, quando, na verdade, seriam as relações sociais que conformam o uso de tecnologias. Como afirma a autora (2014, p. 251), "os novos ambientes tecnológicos reproduzem as relações de força que estão na sociedade", sendo assim a expectativa de geração de cidadania incorre no duvidoso de depositar essa fé na tecnologia quando na realidade a redenção deveria ser esperada da mudança das relações sociais. Para a pesquisadora, a "cultura wiki" seria expressão dessa tendência da comunicação: elaborações voluntárias de qualquer um, cujos conteúdos não precisariam ser revisados antes de uma publicação. Segundo sua análise:

O elogio do "jornalismo participativo" concentra-se no confronto entre os jornalistas (confinados a procedimentos rígidos e orgulhosos de seu "privilégio" como detentores da informação) e o público (isto é, a audiência), desinteressado, ansioso pela verdade e agora possuidor dos meios para obtê-la e revelá-la (MORETZSOHN, 2014, p. 253).

O risco que surgiria dessa situação é que como a crítica seria dirigida ao "poder" dos jornalistas, então não haveria problema em inverter a lógica dos procedimentos elementares para se publicar uma informação. Decorrendo, então, em uma ruptura das regras deontológicas do jornalismo abrindo caminho para a disseminação de boatos e informações falsas, as assim chamadas fake news. Com ressalva, a autora acredita que o "método wiki" até poderia ter utilidade, no entanto, "esse tipo de jornalismo seria viável apenas nessas condições, que supõem um equilíbrio na qualificação de quem participa desse fórum e implicam um alcance limitado" (MORETZSOHN, 2014, p. 254). A falta de qualificação reduziria a credibilidade diante do público em contraposição ao reconhecimento social de mediador que possui o jornalista, pois este estaria onde o público não poderia estar e com a responsabilidade implicada no contato com suas fontes teria o direito de apurar as informações necessárias à sociedade.

Moretzsohn também comenta a respeito da abertura de veículos de comunicação a conteúdo gerado por usuários, utilizando como exemplo o caso da 
rede britânica $B B C$. Suas normas editoriais, diz, estabelecem critérios rigorosos mesmo reconhecendo que as audiências são fornecedoras de material noticioso, onde se deveria:

Garantir "que toda contribuição de terceiros esteja sujeita a avaliação editorial adequada, que essas contribuições sejam feitas de maneira responsável e que, se for o caso, sejam obtidas as devidas autorizações para veiculação". Uma das primeiras preocupações é "não estimular o público a correr riscos ou pôr em risco outras pessoas para obter material a ser enviado para a BBC (MORETZSOHN, 2014, p. 256).

Ainda assim, o jornal britânico The Guardian, no artigo The ethics of citizen photography publicado em agosto de 2012 a respeito da ética do fotojornalismo cidadão, notou problemas na apropriação de imagens geradas pela audiência. Neste caso, a apropriação apressada de conteúdo gerado por usuários sem a devida permissão. Ironicamente, a mesma $B B C$ que pretendia possuir regras rígidas de publicação acabou por não creditar imagens úteis encontradas em perfis de usuários da rede social Twitter por considerá-las de interesse público. Embora, como diz o jornal:

Câmeras digitais e telefones com câmeras tornaram mais fácil capturar momentos dignos de destaque, são as mídias sociais que revolucionaram a fotografia cidadã, fornecendo uma plataforma para compartilhar conteúdo. Com as notícias regularmente aparecendo nas redes sociais, os jornalistas estão se tornando cada vez mais dependentes para notícias em rápido movimento, com alguns agora recorrendo às redes sociais para obter imagens de eventos à medida que eles se desenrolam (THE GUARDIAN, 2012, tradução nossa)

Isto é, em meio a todas essas maneiras de se pensar o jornalismo cidadão, as redes sociais parecem aproximar o jornalismo profissional da audiência e abrir espaço para o engajamento de um tipo de produção não profissional, ao mesmo tempo estabelecendo situações em que ambos os lados são porosos e fazem trocas. Contudo, afirma Moretzsohn (2014, p. 261) “o que subjaz ao elogio da ação direta é essa crença ingênua de um retorno ao senso comum como fonte de verdade". Parece ser fundamental, para a autora, a maneira como essas elaborações se relacionam com instâncias do poder ou eventos radicais como atos terroristas.

\section{“Midialivrismo" e extremismo}

Talvez seja importante neste momento, a partir das considerações feitas, resgatar a noção de "midialivrismo" com o qual identificamos o CMI (Centro de Mídia Independente) discutido anteriormente e recolocarmos o problema com a aproximação que redes sociais criam. Com a invenção de plataformas mais interativas como Facebook, Twitter e Instagram, a velocidade que as informações chegam, repercutem e são compartilhadas, é muito maior que outras plataformas estáticas como websites de jornais profissionais ou mesmo de coletivos de ativistas jornalistas (MALINI; ANTOUN, 2013). Parece-nos, por este motivo, que coletivos de fotojornalismo e jornalismo cidadão utilizam recorrentemente estes espaços, sem contar o apelo do custo que não é evidente aos usuários - apesar de estar em jogo a troca por informações e interações pessoais dentro das plataformas.

Nestes territórios, o midialivrismo teria maior apelo. Para Malini \& Antoun (2013), o midialivrista funcionaria como um hacker de narrativas. Por isso, será muito ligado a noções de ciberativismo com o que reunirá:

Experiências singulares de construção de dispositivos digitais, tecnologias e processos compartilhados de comunicação, a partir de um processo de colaboração social em rede e de tecnologias informáticas, cujo principal resultado é a produção de um mundo sem intermediários da cultura, baseada na produção livre e incessante do comum, sem quaisquer níveis de hierarquia que reproduza exclusivamente a dinâmica de comunicação um-todos. 
(...) Não há qualquer pretensão no midialivrismo de ser mediador de algo ou alguém, senão radicalizar o princípio da "ação direta" que caracteriza a Internet. Ou seja: que cada subjetividade se arrisque a produzir seu movimento na rede. Os midialivristas são sujeitos aparelhados e interfaceados (em sites, blogs e perfis em redes sociais, etc.) que buscam, fora do modus operandi dos veículos de massa, produzir uma comunicação em rede que faz alimentar novos gostos, novas agendas informativas e novos públicos, alargando assim o espaço público midiático, porque consegue hackear a atenção de narrativas que antes se concentravam no circuitão de mídia (MALINI; ANTOUN, 2013, p. 21-24).

A título de exemplo de midialivrismo no Brasil, sem desconsiderar os blogs e outros coletivos de jornalistas profissionais, podemos compreender a chamada Mídia Ninja que resumidamente é um coletivo de ativistas com orientação política, principalmente fotojornalistas cidadãos, voltado para o ambiente web, oriunda da rede de coletivos sociais Fora do Eixo, com ações descentralizadas e que ganhou notoriedade a partir das assim chamadas "Jornadas de Junho" em 2013. Seu funcionamento, nos parece, é a expressão por excelência da relação entre redes sociais, smartphones e a fé na redenção da cidadania. Esta fé seria acionada à medida em que as coberturas por imagens e vídeos seriam capazes de narrar parcialmente com a voz dos ativistas enquanto engajados nos movimentos de rua de que participam. Seria, assim, um contraponto aquilo que normalmente é entendido como ignorado pelos grandes meios de comunicação profissionais, seja por interesse político ou apenas por uma suposta falta de valor noticioso ou comercial.

Então, a partir da condição apresentada por Malini \& Antoun (2013) temos justamente o que Moretzsohn (2014) entende como problemático e ingênuo. Não é fora do comum que muitas das imagens compartilhadas por midialivristas sofram finalizações de edição que enalteçam uma certa dramaticidade com composições e contrastes que no fluxo de imagens visualizadas busca chamar a atenção. Isto não seria um problema se não corressem o risco da estetização, isto é, quando os aspectos formais da imagem vinculam um determinado assunto a uma gramática ornamental que reduz o vínculo do assunto ao acontecimento em benefício de um aspecto visual sedutor, reduzindo a brutalidade da realidade a algo em que o espectador não precisa estar vitalmente testemunhando senão admirando. Além disso, pode ocorrer uma valorização de um formato espetacular, situação que boa parte de seus agentes poderia não estar consciente e que implicaria destituir das coisas e pessoas retratadas a sua realidade. Como notam Malini \& Antoun (2013, p. 24) devem "arcar com uma dupla dificuldade: produzir diferença e evitar, constantemente, a captura espetacular de sua forma de vida.” Evidentemente, este ponto está relacionado a uma tensão entre o valor epistêmico, em que a imagem compartilhada é compreendida como algo que dá a conhecer um evento passado e/ou distante, e o valor estético, quando ela oferece ao espectador uma experiência da sensibilidade e manejo das emoções que pode não ter base no fato que originou a imagem.

Ainda que neste caso as imagens produzidas por midilivristas possam ter formas sutis e agregar valor no exercício da cidadania, elas não são as únicas formas produzidas, pois a depender do polo político pode-se instaurar a destruição de uma cidadania em benefício de modos de existências fascistas. $\mathrm{O}$ ambiente das redes sociais também está sujeito às formas mais perversas e extremas quando estes espaços são ocupados por grupos fundamentalistas ou forças contrárias a um poder estabelecido. Por isso, Moretzsohn (2014) relembra que:

Grupos fundamentalistas islâmicos que filmam a decapitação de suas vítimas e divulgam as imagens na rede ou publicam ali seus manifestos ameaçadores. Ninguém se lembra do “jornalismo participativo" diante do massacre de Beslan, que inclusive levou algumas das principais redes de televisão a reconsiderar a propriedade das transmissões ao vivo, não só para poupar os espectadores de cenas chocantes como para se resguardar da eventualidade de os terroristas usarem o poder da imagem ao vivo para impor suas exigências diante de uma audiência perplexa (MORETZSOHN, 2014, p. 263). 
Então, uma objeção que se poderia fazer é: nestes casos, as plataformas, por suas responsabilidades envolvidas na transmissão de cenas de violência, fazem controles de proteção a seus usuários. Contudo, como diz David Miller:

As mídias sociais representam uma aceleração significativa na possibilidade de a comunicação se tornar mais visual, no sentido de que agora é possível manter algo muito próximo a uma conversa quase inteiramente sem voz ou texto (MILLER, 2016, p. 177, tradução nossa).

De modo que seria interessante uma compreensão de como os usuários se apropriam dessas imagens, mesmo as mais violentas ou espetacularizadas. Ou seja, o que faz circular com elas: afetos, testemunhos, valores normativos, etc. E todo esse circuito pode já ter sido ativado antes mesmo de qualquer tipo de controle feito pelas plataformas, se assim fosse aceitável do ponto de vista da censura, sem tempo de impedir a virulência de algumas imagens.

Ainda que (MORETZSOHN, 2014; 2019) pareça optar por um profissionalismo regido por uma deontologia jornalística com valores internacionalmente reconhecidos, devemos lembrar que nem sempre, e, sobretudo, nesse período da violência fundamentalista relatada, jornais sérios não se apropriaram de diversas dessas imagens. Uma série delas, inclusive, foi premiada no evento anual francês de correspondentes de guerra de 2014, Prix Bayeux-Calvados, como veremos a seguir.

\section{Reportagens “insustentáveis”}

Figura 1- Syrie: La barbarie au quotidien

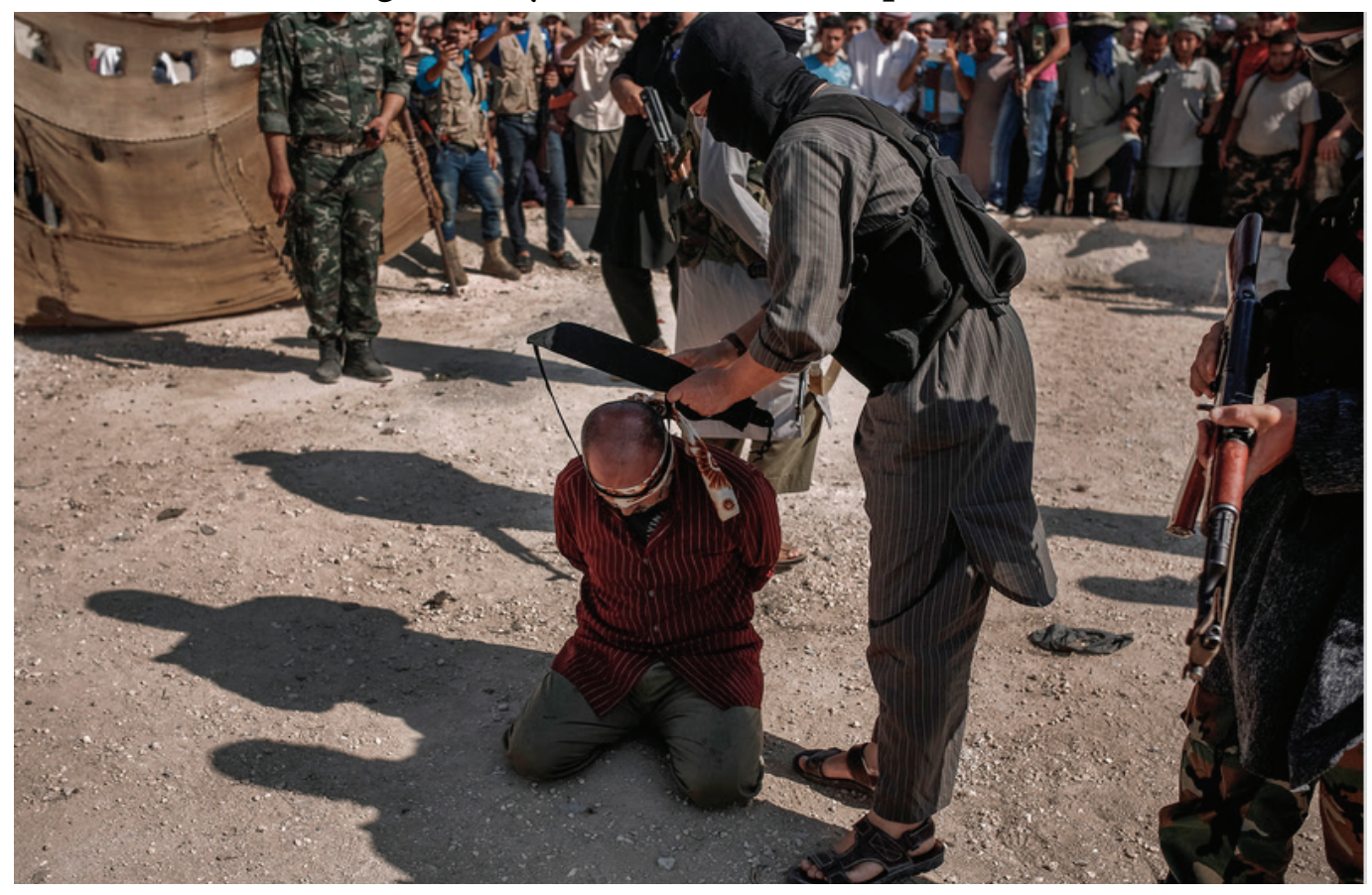

Foto: Emin Özmen, 2013.

Houve uma polêmica suscitada a partir da reportagem fotográfica Syrie: La barbárie au quotidien (2013) feita pelo turco Emin Özmen, ganhador do prêmio de público no Prix Bayeux-Calvados de 2014. Tratou-se de uma série de nove fotografias, dentre elas decapitações públicas, promovidas pela facção armada ISIS (Estado Islâmico do Iraque e al-Sham) em quatro vilarejos da região de Aleppo, Ehtemlat, A’Azaz, Saran e Keferghan, em 31 de agosto de 2013. Estas fotografias suscitaram debates no seio do júri profissional que escolheu não premiar seu trabalho. Além disso, veículos de comunicação, inclusive o jornal Sabah, onde trabalhava o fotojornalista, não aceitaram publicá-las, com as exceções de Time e Paris Match. Aqueles que negaram o fizeram sob a argumentação de que elas eram ima- 
gens sangrentas insustentáveis, e, quando muito, promotoras de propaganda, não sendo compreendidas como trabalho jornalístico.

Para o fotógrafo e jurado, Ammar Abd Rabbo, foi chocante e entristecedor descobrir que a escolha do prêmio do público do Prix Bayeux-Calvados se deu diante de parentes de James Foley, jornalista americano decapitado pelo ISIS. Em seu texto opinativo publicado em outubro de 2014 no blog A l'oeil - journalisme \& photographie e replicado no Rue89 - Le Nouvel Observateur, o fotógrafo comenta a distinção do júri profissional em premiar o trabalho "sóbrio e estético" de Mohammed Al Cheikh, da AFP, que ilustrava as manifestações e violências contra a maioria xiita no Bahrein. Sob sua argumentação, colocam-se não apenas verdadeiras questões éticas da profissão, mas também da sociedade que vivemos. O jurado afirma que a produção de Özmen não foi uma reportagem e nem um trabalho jornalístico. Para ele, o jornalista é aquele que "questiona, que relativiza, que coloca em perspectiva, que verifica os fatos", e na série fotográfica não se tinha nada disso, pois o ISIS levava ao local o fotógrafo e suas vítimas, e diante dele as executava para que uma imagem da ação seja feita e circulada. Segundo Rabbo, tratou-se de uma operação de propaganda ou de comunicação que a organização:

Deseja mostrar que ela é a mais perversa, a mais intransigente, e estas fotos vem perfeitamente servir ao seu discurso. Nós não sabemos nada sobre as vítimas. Quais seus nomes? Onde foram julgadas? Por quem? Como elas foram capturadas? (RABBO, 2014, tradução nossa).

Então o jornalista sem nenhum meio de verificar, nem fornecer informações sobre as execuções, transforma-se em retransmissor da comunicação do ISIS acreditando fazer um bem à sua comunidade.

Rabbo em seu texto clama, assim como outros jornalistas e representantes de veículos de comunicação do Ocidente, que o correto seria dizer não ao ISIS, posicionando-se contra a difusão de imagens de execução, não apenas por solidarizar-se ao seu confrade James Fouley, mas àqueles sírios anônimos mortos pelos mesmos assassinos. Mesmo que, por outro lado, se defendesse apresentar a realidade síria como o pretende Emin Özmen:

"Como um ser humano, eu desejaria nunca ter visto o que vi. Mas como jornalista eu tinha uma câmera e uma responsabilidade. Eu tinha a responsabilidade de compartilhar o que vi naquele dia. Por isso estou fazendo esta declaração e por isso tirei aquelas imagens.” (ÖZMEN, s.d.).

No entanto, diz o jurado de Bayeux, a realidade síria está lá com dezenas e centenas de mortos ao dia, pelos bombardeios do regime de Assad, ao lado de decapitações e crucificações, mas não são vendáveis, ou valem menos que uma decapitação (RABBO, 2014). Trata-se, no argumento de Rabbo, da realidade do trabalho jornalístico, desolador, mas necessário enfrentar, diferente do que seria a busca pela imagem sensacionalista ou sem critérios.

Conclui, Ammar Rabbo, que não se poderia compreender nada a partir desse tipo de imagem. Pois apesar de tudo, as imagens apenas indignariam, horrorizariam, e nos deixaria diante de um registro de voyeurismo, "de joelhos para o executor, enquanto afia sua lâmina", que aquela da análise e compreensão; as vítimas foram desumanizadas. Sua preocupação fica clara com o tratamento rigoroso das informações não verificadas em tempos de redes sociais, mesmo em se tratando de jornalistas profissionais, em um momento de crise econômica que atravessa o trabalho jornalístico que faz violar princípios e a moral. Para ele, o público ficaria sujeito a não saber diferenciar uma reportagem de uma propaganda terrorista. E neste caso, os indivíduos que receberiam as imagens em suas redes ainda poderiam compartilhá-las em reação oposta ou a favor, potencializando ainda mais a difusão da mensagem do grupo extremista.

Para o psicanalista Vincent Magos, trata-se não apenas de uma questão de dignidade das vítimas ou jogar o jogo dos jihadistas, mas que as imagens não nos 
deixariam psiquicamente a escolha que não fosse entre a posição da vítima ou do algoz. Para Magos, uma foto de um jihadista preparando-se para matar é traumatizante, pois ela força a imaginar o horror que se segue. Ainda pior, leva-nos a nos identificarmos com um dos protagonistas: a vítima ou seu algoz. A esta situação ele contrasta a foto de Edward Adams sobre um general vietnamita apontando seu revólver a um vietcongue. Segundo ele, essa fotografia nos colocaria numa terceira posição, a da testemunha, e por isso nos revoltaria e como ocorreu tornou-se símbolo de uma "guerra suja" a acabar.

Figura 2 - Execução de vietcongue em Saigon

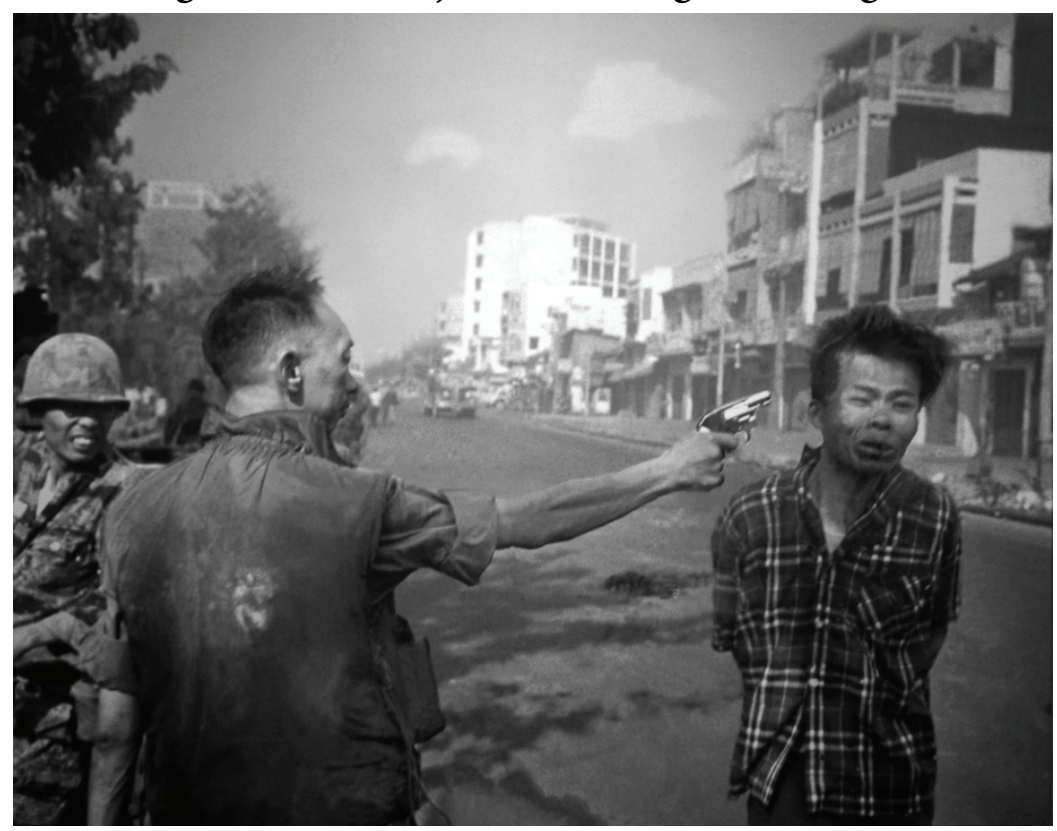

Foto: Eddie Adams, 1968/AP.

O psicanalista apresenta o argumento de que um filme, por mais realista e cru, sabemos tratar-se de uma ficção e a todo momento podemos nos retirar da cena, interrogamo-nos sobre sua realização, as trucagens, etc. Mas no caso de uma fotografia de execução, ela é cuidadosamente planejada pelo transgressor, pois registra a cena como quer, por seu dispositivo, e assim somos colocados num ato criminoso, como o quer o criminoso. Como diz, "quer fazer a todos seus cúmplices: este é o mecanismo trabalhado pelo estupro de guerra (manter ou não a criança nascida da transgressão) ou na obrigação de mutilar ou matar um próximo" (MAGOS, 2014).

Conclui o psicanalista que, então, com o avanço de câmeras compactas, a posição de terceira pessoa é assimilada, e afim de recusar este lugar deve-se desviar o olhar das execuções e de sua difusão pelas mídias, confiante de que um mundo de cultura é capaz de lutar contra a barbárie. Desse modo, vemos que mesmo no jornalismo profissional fotografias como a de Özmen entram no circuito de afetos do público que as compartilha e premia, muitas vezes servindo de parâmetros da liberdade de tudo fotografar e circular. Parecem fazê-lo acreditando enaltecer valores democráticos quando em realidade podem estar recrudescendo sintomas brutais que destroem a democracia, seja ao mostrar cruamente algumas violências ou apostar que um enviesamento equivocado sobre a realidade, negada no jornalismo profissional, deve ser respeitada.

\section{Considerações finais}

Esperamos ter apresentado algumas das possibilidades do chamado fotojornalismo cidadão e as contradições no que tange às expectativas de que a tecnologia pode ser redentora, isto é, quando o cidadão munido da capacidade de representar 
seu cotidiano em benefício de sua cidadania também apresenta o potencial oposto, pois as imagens podem sofrer interferência da própria memória, no sentido de memória social, além do uso ou na circulação que as fotografias estão sujeitas. A matéria emocional compõe outras sensações, tornam possíveis relações enganosas e permitem outros usos ideológicos daquelas imagens que pareciam todas tomadas de sentido a uma certa comunidade. Os próprios indivíduos podem produzir imagens tendo em vista a sua circulação com envolvimento que produz prestígio e visibilidade, gerando bolhas que intensificam não a cidadania ou um consenso geral sobre o que é verdadeiro, mas os afetos mais terríveis que vinculam esses indivíduos uns aos outros e que servem como legitimadores que se retroalimentam.

Parece-nos um campo rico para um estudo etnográfico a quem queira conhecer mais da cultura material sem um viés moralista, como diz Daniel Miller (2010), sobretudo levando-se em conta a apropriação de smartphones como maneira de compartilhar experiências, sejam elas a vida cotidiana do usuário ou suas manifestações políticas. Além disso, entender como relações tipicamente arcaicas de trocas ainda permanecem da maneira mais sutil como nos coletivos midialivristas, poderia auxiliar a compreender como funcionam as bolhas e suas fontes legitimadoras nas redes sociais.

Compreender essas relações, como os "trecos" nos acompanham e nos fazem em meio aos desenvolvimentos tecnológicos, em um mundo de coisas cada vez mais interconectadas, permite compreender as contradições a que estamos sujeitos. Além de desvendar situações muitas vezes consideradas banais de tão próximas que estão em nosso cotidiano, quando de fato são complexas e lançam luz sobre as dinâmicas das normas culturais enquanto nos relacionamos através do consumo e de uma cultura material, por exemplo, se quisermos entender como redes extremistas parecem desconectadas das fontes mais tradicionais de conhecimento.

Por fim, pensamos o fotojornalismo profissional como sujeito a interferências similares à da produção amadora, seja na circulação de imagens, apesar do interesse econômico e legitimação de uma narrativa dominante, ou na própria produção de imagens quando um fotojornalista acredita que uma oportunidade não pode ser perdida por responsabilidade jornalística ou mesmo no voluntarismo em contribuir com o fim de algum conflito. A distinção, nos parece, é que o fotojornalismo profissional está sujeito ao escrutínio público e seus mecanismos deontológicos estão sempre colocando em exame como se legitima sua credibilidade, enquanto no fotojornalismo cidadão, quando não está associado ao filtro do jornalismo tradicional, sua legitimação ocorre por meios menos racionais e ligados aos circuitos afetivos de sua comunidade. Um exame mais detido a este respeito poderia contribuir a pensarmos até onde os mecanismos de validação de credibilidade utilizados nos últimos tempos como os fact-checking funcionam em ambas as condições e conseguem se fazer úteis para aqueles que quase sempre questionam a "mídia tradicional".

\section{Referências}

APGAUA, Renata. O Linux e a perspectiva da dádiva. Horizontes Antropológicos, Porto Alegre, ano 10, n. 21, p. 221-240, jan./jun. 2004. Disponível em: http:// www.scielo.br/scielo.php?script=sci_arttext\&pid=S0104-71832004000100010. Acesso em: 22 jun. 2020.

BONI, Paulo César; SOUZA, Fabio. Fotojornalismo cidadão: a fotografia a serviço da cidadania. Revista Studium 27, Campinas. Disponível em: http://www. studium.iar.unicamp.br/27/2/index. Acesso em: 22 jun. 2020. 
DELOITTE. Global Mobile Consumer Survey 2017. Disponível em: https:// www2.deloitte.com/br/pt/pages/technology-media-and-telecommunications/articles/mobile-survey.html. Acesso em: 22 jun. 2020.

DOUGLAS, Mary; ISHERWOOD, Baron. O mundo dos bens: para uma antropologia do consumo. Rio de Janeiro: UFRJ, 2004.

FGV. 29a Pesquisa Anual do Uso de TI. Disponível em: https://eaesp.fgv.br/ensinoeconhecimento/centros/cia/pesquisa. Acesso em: 22 jun. 2020.

Franceinter. Syrie: jusqu'où montrer la barbarie? Disponível em: http://www. franceinter.fr/blog-autopsie-dune-photo-syrie-jusqu-ou-montrer-la-barbarie. Acesso em: 22 jun. 2020.

France24. Prix Bayeux : un reportage insoutenable en Syrie primé par le public. Disponível em: http://www.france24.com/fr/20141012-prix-bayeux-images-decapitation-syrie-recompensees-le-public-ei-jihadistes. Acesso em: 20 jun. 2020.

KOPYTOFF, Igor. A biografia cultural das coisas: a mercantilização como processo. In: APPADURAI, ARJUN. A vida social das coisas. Niterói: EDUFF, 2008.

MALINI, Fábio; ANTOUN, Henrique. A internet e a rua: ciberativismo e mobilização nas redes sociais. Porto Alegre: Sulina, 2013.

MAGOS, Vincent. Il faut refuser de regarder les images des mises à mort. Slate, 15 de setembro de 2014. Disponível em: http://www.slate.fr/story/92145/refuser-regarder-images-etat-islamique. Acesso em: 20 jun. 2020.

MAUSS, Marcel. Ensaio sobre a dádiva: forma e razão da troca nas sociedades arcaicas. In: MAUSS, Marcel. SOCIOLOGIA e antropologia. São Paulo: EPU, 1974

MILLER, Daniel. Visual Images. In: MILLER, Daniel et al. How the World Changed Social Media. London: UCL Press, 2016.

MILLER, Daniel. Trecos, troços e coisas. Estudos antropológicos sobre a cultura material. Rio de Janeiro: Zahar, 2010.

MORETZSOHN, Sylvia. O "Jornalismo cidadão" e o mito da tecnologia redentora. Brazilian Journalism Research, Brasília: SBPJor, v. 11, n. 2, 2014. Disponível em: https://doi.org/10.25200/BJR.v10n2.2014.751. Acesso em: 20 jun. 2020.

MORETZSOHN, Sylvia. O Joio, o Trigo, os Filtros e as Bolhas: uma discussão sobre fake news, jornalismo, credibilidade e afetos no tempo das redes. Brazilian Journalism Research. Brasília: SBPJor, v. 15, n. 3, 2019. Disponível em: https://doi. org/10.25200/BJR.v15n3.2019.1188. Acesso em: 21 dez. 2020

MURDOCK, Graham. Networking the commons: convergence culture and the public interest. In: Relocating Television: Television in the Digital Context. New York: Routledge, 2010, p. 224-237.

ÖZMEN, Emin. Emin Özmen. Disponível em: https://www.eminozmen.com. Acesso em: 20 jun. 2020. 
PARIS MATCH. Montrer l'insoutenable. 2013. Disponível em: http://www.parismatch.com/Actu/International/Montrer-1-insoutenable-527254. Acesso em: 20 jun. 2020.

RABBO, Ammar Abd. Prix Bayeux-Calvados: Pourquoi je n’ai pas apprécié le prix du public! A l'oeil, 13 de outubro de 2014. Disponível em: http://www.a-l-oeil.info/ blog/2014/10/13/prix-bayeux-calvados-pourquoi-je-nai-pas-apprecie-le-prix-du-public-par-ammar-abd-rabbo. Acesso em: 20 jun. 2020.

RABBO, Ammar Abd. Pourquoi je ne suis pas d'accord avec le choix du public au prix Bayeux des correspondants de guerre. Rue 89, 21 de novembro 2016. Disponível em: http://rue89.nouvelobs.com/2014/10/13/pourquoi-nai-aime-choix-public-prix-bayeux-correspondants-guerre-255449. Acesso em: 20 jun. 2020.

SKOGESETH, Egil. Indymedia - Journalistic Anarchy on WWW. Bergen, 2005. Dissertação (Mestrado em Estudos de Mídia) - University of Bergen, Berga, Noruega. 